\title{
Commentary: Ongoing challenges for optimal strategy of aortic arch surgery
}

\author{
Hidefumi Nishida, MD, and Takeyoshi Ota, MD, $\mathrm{PhD}$
}

\footnotetext{
From the Section of Cardiac Surgery, Department of Surgery, The University of Chicago, Chicago, Ill. Disclosures: Authors have nothing to disclose with regard to commercial support.

Received for publication Feb 11, 2019; accepted for publication Feb 11, 2019; available ahead of print March 20, 2019.

Address for reprints: Takeyoshi Ota, MD, PhD, Section of Cardiac and Thoracic Surgery, Department of Surgery, Center for Aortic Diseases, The University of Chicago, 5841 S Maryland Ave, MC5040, Chicago, IL 60637 (E-mail: tota@bsd.uchicago.edu).

J Thorac Cardiovasc Surg 2020;159:390-1

$0022-5223 / \$ 36.00$

Copyright (c) 2019 by The American Association for Thoracic Surgery

https://doi.org/10.1016/j.jtcvs.2019.02.059
}

We congratulate Wang and colleagues ${ }^{1}$ on their large cohort study in China of aortic arch surgery in the adult population with hypothermic circulatory arrest and unilateral antegrade cerebral perfusion. This article provides convincing findings because of not only the large number of the cohort but also minimizing possible confounding factors by using the standardized surgical technique.

Optimal surgical strategies of aortic arch surgery have been investigated by many investigators, but it still remains challenging. This study described detailed comprehensive data with excellent clinical outcomes. The study showed 30 -day mortality was $6.1 \%$ and permanent neurologic dysfunction incidence was $4.8 \%$. It is comparable with the outcomes of other high-volume centers, such as Okita and colleagues, who reported that the mortality of total arch replacement was $4.5 \%$ and permanent neurologic deficit was $3.3 \%$. $^{2,3}$

It is important to mention that the incidence of paraplegia in this study is relatively low $(2.0 \%)$ when they used the frozen elephant trunk technique in most of the cases. It has been reported that the use of frozen elephant trunk is associated with increased risk of postoperative paraplegia. ${ }^{4}$ It was identified in the study that age and DeBakey type I dissection were independent predictors of paraplegia, but not the use of the elephant trunk technique. The authors mentioned that this result might have been due to the shorter lower body circulatory arrest time compared with the other studies. ${ }^{5,6}$ Further investigations would be warranted in this matter.

There are several points to be addressed in understanding this article correctly. First, the mean patient age was 47 years old, which is relatively young compared with other reports, ${ }^{2,3}$ and might have been a contributor for clinical outcomes in this study. Second, this study includes nondissection patients $(9.4 \%)$ undergoing aortic arch surgery, and more than $40 \%$ of dissection patients had subacute or chronic dissection. In general, the outcome of studies. ${ }^{5,6}$

\section{References}

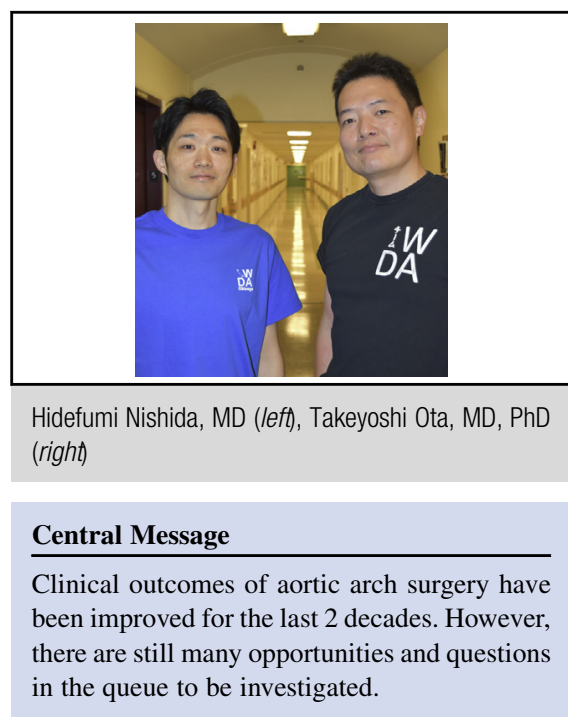

See Article page 374.

surgery for nonacute aortic dissection is better than acute aortic dissection. ${ }^{7,8}$ Third, they reported that the risk for permanent neurologic dysfunction and mortality increased when unilateral antegrade cerebral perfusion time was longer than 38 minutes and decreased when nasopharyngeal temperature at the time of circulatory arrest was lower than $24^{\circ} \mathrm{C}$. It is generally difficult to assess an event with 2 variables that both are confounding factors for the event. Fourth, it is important to note that the definition of unilateral antegrade cerebral perfusion time in this study is the period from the initiation of unilateral antegrade cerebral perfusion to the reconstruction of left carotid artery (ie, duration of the distal aortic anastomosis and left carotid anastomosis). This definition appears to make their "circulatory arrest time" shorter than it really is as well as ones in the other

Although aortic arch surgery has emerged as an important treatment strategy and its clinical outcomes have improved during the last 2 decades, there are still many opportunities and questions in the queue to be investigated.

1. Wang X, Yang F, Zhu J, Liu Y, Sun L, Hou X. Aortic arch surgery with hypothermic circulatory arrest and unilateral antegrade cerebral perfusion: perioperative outcomes. J Thorac Cardiovasc Surg. 2020;159:374-87.e4. 
2. Okita Y, Okada K, Omura A, Kano H, Minami H, Inoue T, et al. Total arch replacement using antegrade cerebral perfusion. J Thorac Cardiovasc Surg. 2013;145: S63-71.

3. Minatoya K, Inoue Y, Sasaki H, Tanaka H, Seike Y, Oda T, et al. Total arch replacement using a 4-branched graft with antegrade cerebral perfusion. J Thorac Cardiovasc Surg. October 17, 2018 [Epub ahead of print].

4. Leontyev S, Borger MA, Etz CD, Moz M, Seeburger J, Bakhtiary F, et al. Experience with the conventional and frozen elephant trunk techniques: a single-centre study. Eur J Cardiothorac Surg. 2013;44:1076-82; discussion 1083 .

5. Zierer A, Risteski P, El-Sayed Ahmad A, Moritz A, Diegeler A, Urbanski PP. The impact of unilateral versus bilateral antegrade cerebral perfusion on surgical outcomes after aortic arch replacement: a propensity-matched analysis. J Thorac Cardiovasc Surg. 2014;147:1212-7; discussion 1217-8.

6. Angeloni E, Melina G, Refice SK, Roscitano A, Capuano F, Comito C, et al. Unilateral versus bilateral antegrade cerebral protection during aortic surgery: an updated meta-analysis. Ann Thorac Surg. 2015;99:2024-31.

7. Rylski B, Milewski RK, Bavaria JE, Branchetti E, Vallabhajosyula P, Szeto WY, et al. Outcomes of surgery for chronic type A aortic dissection. Ann Thorac Surg. 2015;99:88-93.

8. Sun LZ, Qi RD, Chang Q, Zhu JM, Liu YM, Yu CT, et al. Is total arch replacement combined with stented elephant trunk implantation justified for patients with chronic Stanford type A aortic dissection? J Thorac Cardiovasc Surg. 2009;138: 892-6. 